1 Bailey S, Gerada C, Lester H, Shiers D. The cardiovascular health of young people with severe mental illness: addressing an epidemic within an epidemic. Psychiatrist 2012; 36: 375-8.

2 Nielsen J, Skadhede S, Correll CU. Antipsychotics associated with the development of type 2 diabetes in antipsychotic-naive schizophrenia patients. Neuropsychopharm 2010; 35: 1997-2004.

3 Lahti M, Tiihonen J, Wildgust $H$, Beary M, Hodgson R, Kajantie E, et al Cardiovascular morbidity, mortality and pharmacotherapy in patients with schizophrenia. Psychol Med 2012; 42: 2275-85.

4 Kilbourne AM, Morden NE, Austin K, Ilgen M, McCarthy JF, Dalack G, et al. Excess heart-disease-related mortality in a national study of patients with mental disorders: identifying modifiable risk factors. Gen Hosp Psychiatry 2009; 31: 555-63.

5 Beary M, Hodgson R, Wildgust HJ. A critical review of major mortality risk factors for all-cause mortality in first-episode schizophrenia: clinical and research implications. J Psychopharmacol 2012; suppl. 26: S52-61.

Richard E. Hodgson, Consultant Psychiatrist, Lyme Brook Centre, Stoke on Trent, email: RichardE.Hodgson@northstaffs.nhs.uk, Hiram Wildgust Managing Director, Hiram Consulting Ltd, Pontefract, Michael Beary, Consultant Psychiatrist, The Priory, London.

doi: $10.1192 / p b .37 .1 .33 a$

\section{latrogenicity: are we largely to blame for this epidemic?}

Notwithstanding the premorbid genetic and psychosocial predispositions Bailey et al refer to, ${ }^{1}$ the authors also correctly highlight the incontrovertible evidence that the obesity and metabolic syndrome epidemic we are facing is largely drug induced, as highlighted by the EUFEST study. ${ }^{2}$ Given this, we must accept that we are essentially complicit in greatly increasing our own patients' morbidity and mortality, and that this 'epidemic within an epidemic' is iatrogenic. I cannot help but wonder whether we, as clinicians, tend to ignore a side-effect which we consider to be 'benign', in relation to the perceived lack of an immediate need to address it urgently, as opposed to, for example, an acute extrapyramidal side-effect, massively raised prolactin or marked electrocardiogram changes. I wonder whether our complacency in addressing this adverse effect profile may be borne out of a sense of our own helplessness. That is to say, because there is no straightforward solution to this multifaceted problem, we choose to ignore or at least sidestep the issue. It is precisely because of the creeping, insidious nature of these obesityrelated problems that we are allowing them to develop into an 'epidemic' of such proportions.

We must ask ourselves whether it is morally acceptable to treat chronic and enduring mental illness at the expense of inflicting chronic and enduring physical illnesses. As the authors allude, if we actually bothered to ask our patients, particularly the younger ones, what it is they would be most distressed by - continued mental illness or aggressive weight gain - would it really be so surprising that a sizeable proportion would prefer to remain distressed by (or learn to cope with) their psychiatric symptoms than become morbidly obese? Should this really come as a shock to us, given the strongly body-conscious world in which we live? I suspect that our priorities as psychiatrists may not be entirely aligned with those of many of our patients. Is there a doctor-patient risk-benefit analysis mismatch at play here?

But are we really improving our patients' quality of life and promoting social inclusion by treating one stigmatising condition for another, which arguably carries even greater prejudice? After all, most of the population view morbidly obese people not only as a repulsive eyesore, but tend to apportion blame. Many view obesity as a self-inflicted condition, borne purely out of laziness and gluttony, and tend to make extremely pejorative judgements.

Notwithstanding this, although antipsychotics are the only truly effective weapons in our armament against chronic psychotic disorders, it is incumbent on us to make prescribing decisions which take from the outset the potential ramifications of such physically and socially disabling adverse effects into account.

At the end of the day, if I was a patient, I would not be happy to learn that I had developed a serious, chronic physical disorder with many potential multisystem complications (such as diabetes) as a result of taking a drug which I probably was not keen to take in the first place anyway, and was never fully appraised of the risks. We must never be economical with the truth about the drugs we are all too happy to dish out.

1 Bailey S, Gerada C, Lester H, Shiers D. The cardiovascular health of young people with severe mental illness: addressing an epidemic within an epidemic. Psychiatrist 2012; 36: 375-8.

2 Kahn RS, Fleischhacker WW, Boter H, Davidson M, Vergouwe Y, Keet IP, et al. Effectiveness of antipsychotic drugs in first-episode schizophrenia and schizophreniform disorder: an open randomised clinical trial. Lancet 2008; 371: 1085-97.

Aashish Tagore, specialist registrar in adult psychiatry, Mersey Care NHS Trust, email: aashishtagore@hotmail.com

doi: 10.1192/pb.37.1.34

\section{Physical health epidemic in mental health}

We would very much welcome the focus on physical health from secondary mental health, as advocated by Bailey et al. ${ }^{1}$ However, we would like to raise the following points.

The Quality Outcomes Framework ${ }^{2}$ now includes HbA1c levels recorded in the past 15 months to identify diabetes for patients aged 40 years and over with schizophrenia, bipolar affective disorder and other psychoses (MH20). It is worth noting that the World Health Organization has included HbA1c in its diagnostic criteria for diabetes and this is also being backed up by the National Institute for Health and Clinical Excellence. ${ }^{3}$ We think that it is important to have HbA1c levels recorded, especially in patients on antipsychotics.

The incidence of metabolic syndrome in psychiatric patients has been covered recently in this journal, ${ }^{4}$ but Bailey et al could have highlighted the need for baseline physical health monitoring before commencing on antipsychotics. Moreover, there is a known higher incidence of diabetes in patients with psychosis. Therefore, psychiatrists play a major role in reminding other clinicians and reiterating in their communication to general practitioners the importance of following parameters such as weight, blood pressure and glucose levels in the early weeks, so the primary care team are aware and the patients are appropriately followed up and supported.

Bailey et al seem to be suggesting that antipsychotics have no role in the management of psychosis and the disorder can be treated with a multiprofessional approach. It might have been better to mention the impact of duration of untreated psychosis on the long-term patient-related outcomes, ${ }^{5}$ and so I would have thought that antipsychotics would be the essential 